\title{
EVALUATION OF DEVELOPED OILSEED EXPRESSION MACHINE
}

\author{
A. A. El Nakib ${ }^{(1)}$, H. A. Abdel Mawla ${ }^{(2)}$
}

A. M. Rasmy ${ }^{(3)}$, M. M. Geasa ${ }^{(4)}$

\section{ABSTRACT.}

The aim of this study was to develop and test an oilseed expression machine for oil production. The tested parameters were: (1) Machine setting of one stage and double stage expression (2) Screw speeds of 30, 50, 70 and $90 \mathrm{rpm}$ (3) Cake output clearance 0.5, 0.8, 1.1 and $1.4 \mathrm{~mm}$ (4) for double stage expression setting intermediate choke gap of 0.6, 0.8, 1.0 and $1.2 \mathrm{~mm}$. and (5) Moisture content of oilseed $6 \%, 8 \%$ and $10 \%$.

Results obtained increasing in expression efficiency by: reducing the choke gap, reducing the screw rotational speed, increasing seeds moisture-content to $8 \%($ d.b), and using double stage machine.

Maximum oil expression efficiency was $86 \%$ at $0.5 \mathrm{~mm}$ choke gap, 30 rpm screw rotational speed, $6 \%$ moisture content and two stage machine setting with 0.6 mm intermediate choke gap. On the other hand, minimum oil expression efficiency was $52 \%$ at $1.4 \mathrm{~mm}$ choke gap, $90 \mathrm{rpm}$ screw rotational speed, $6 \%$ moisture content and single stage machine.

The evaluated parameters affecting the expression process, oil productivity, expression efficiency, expressed oil temperature, oil production cost are discussed in the paper.

\section{1 - INTRODUCTION.}

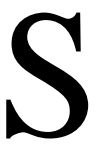
eparation of oil from oilseeds is an important processing operation. The process employed has a direct effect on the quality and quantity of oil obtained from the oilseeds. Mechanical pressing of oilseeds is the most widely used method for oil expression in the world. However, the mechanical oil expellers (screw presses) employed for this purpose leave more than $15 \%$ of the expressible oil in the deoiled cake, so that a large quantity of edible oil is

(1) and (3) Prof. and Assoc. Prof., of Agric. Eng., Fac. of Agric. Eng.., Al-Azhar University.

(2) and (4) Prof. and Assoc. Lect., of Agric. Eng., Fac. of Agric., Eng. Dep. Al-Azhar University. Assiut branch. 
not available for human consumption. To narrow edible oils productionconsumption gap a modified oil expeller was developed based on principle of single feed double stage compression Al-Ashry(1999) showed that the factors contributing to extraction efficiency may be classified into two general categories: (1) those related to the properties of the oilseed itself, and (2) those related to conditions under which the seed is expressed. The factors that influence the yield of oil from a press include:

The maturity and growth conditions of the raw material, the extent of disruption of cell structure, the resistance of the solids to mechanical deformation, the rate of increase in pressure, the time of pressing, the maximum pressure applied, the thickness of the pressed solids, the temperature of solids and liquid and the viscosity of the expressed liquid.

Amin et. al. (2007) reported that edible oils are the least food products self-sufficient in Egypt, as its self-sufficiency rate is less than $10 \%$, and its imports value per annum mount up to nearly $1 \$$ billion. So, Egyptian agricultural policy should be aimed to increase oil yield, not only by increasing cultivated oilseeds area or by increasing oilseeds productivity per unit area, but also by maximizing the extracted oil from oilseeds.

Beerens (2007) stated that mechanical screw pressing is the most popular method in the world to separate oil from vegetable oilseeds on small to medium scale. Reasons for its popularity are that the machines require low initial and operation investments, can easily be operated, maintained and adopted by semi-skilled personnel, can be adapted quickly for processing of different kinds of oilseeds, The oil expulsion process is continuous with product obtained within a few minutes of start of the processing operation; The safety and simplicity of the whole process is advantageous over the more efficient solvent extraction equipment. Furthermore, it is possible to manufacture screw presses locally creating additional local employment. Both the oil and the de-oiled press cake obtained using screw presses are free of solvents and other chemicals as opposed to the more efficient solvent extraction method. 
The objective of this study was to evaluate developed expression machine. Some factors affecting the performance of the developed prototype such as screw speed, choke gap clearance. Machine setting and seed moisture-content are studied and discussed.

\section{2 - MATERIALS AND METHODS.}

Materials:

\section{Oil expression-machine:}

The fabricated expression machine was manufactured at a workshop in Mahala (المحله). Figs. 1 and 2 show that the fabricated oil expression machine consists of:

a) Frame: The frame has the dimensions $200 X 42 X 60 \mathrm{~cm}$ made from iron angles $(7.5 \times 7.5 \mathrm{~cm})$ welded together.

b). Choke mechanism A choke regulator permits a final adjustment of the expression machine pressure. The choke gap may be adjusted to change the pressure according to used oilseed condition.

c) Hopper The hopper was made from galvanized iron sheet as conical shape. Cone side incline is $60^{\circ}$ ( $\tan 60$ is much greater than the coefficient of friction of the seed in contact with galvanized iron) to ensure free flow of seeds into the expression unit.

d) Barrel (cage) The cage consists of flat steel bars assembled to be parallel to the worm shaft. The whole set of bars functions as a screen, allowing the oil to pass but not the solids. The spacing of the bars ranged from 0.125 to $0.5 \mathrm{~mm}$. The even spacing can't be achieved.

e). Screw Fig. (2) shows two different settings of screw used in the developed expression machine. The first was used to one stage oil expression machine setting and the second was used as two stage expression machine unit. Two screw sets can be used in the developed machine. A screw with an additional intermediate choke hypothesized that this would facilitate pressing the fed oilseed twice rather than once prior to its exit from the barrel which, may maximize the efficiency of oil recovery without generating the high pressures that absorb power and cause excessive wear of parts.

f) Electrical motor and power transmission.

Electrical motor of $(15.4 \mathrm{~kW}), 970 \mathrm{rpm}$ was used with a differential gearbox of speed reduction 7:1. A set of pulleys that transmit power from 
the motor to the gearbox was used to vary the oil extraction screw rotational speed.
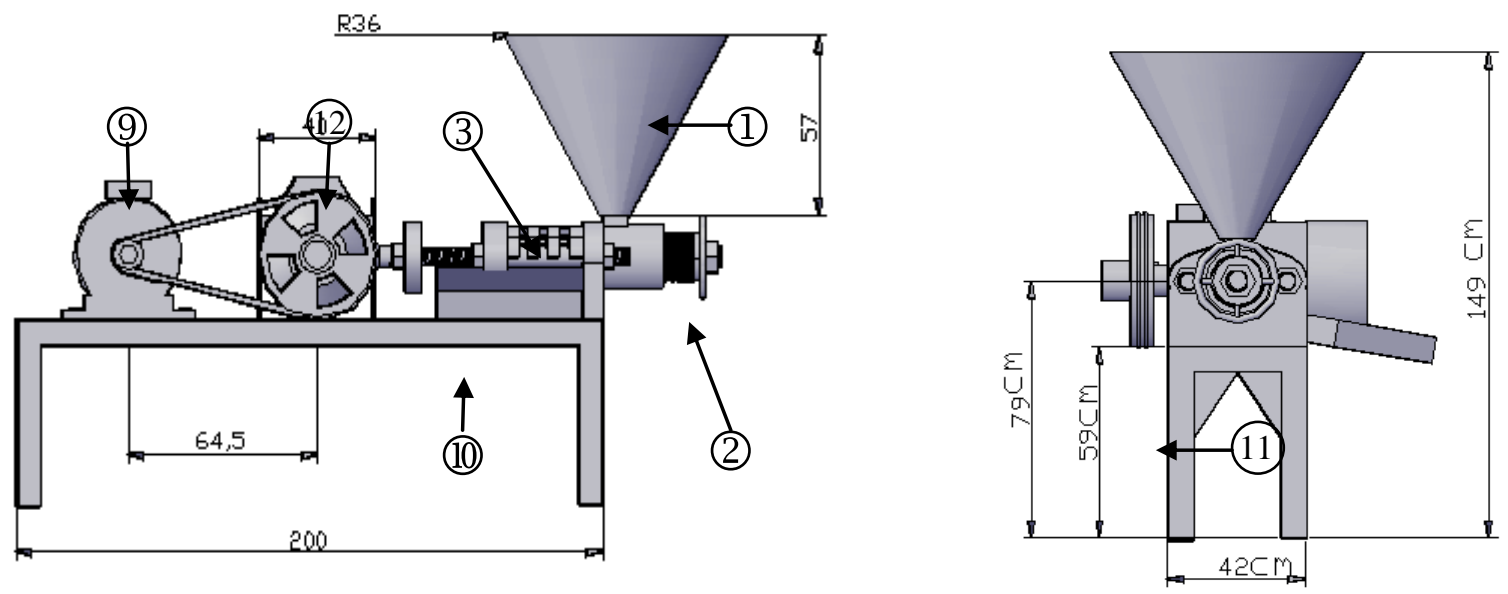

Figure(1): Expression machine components.

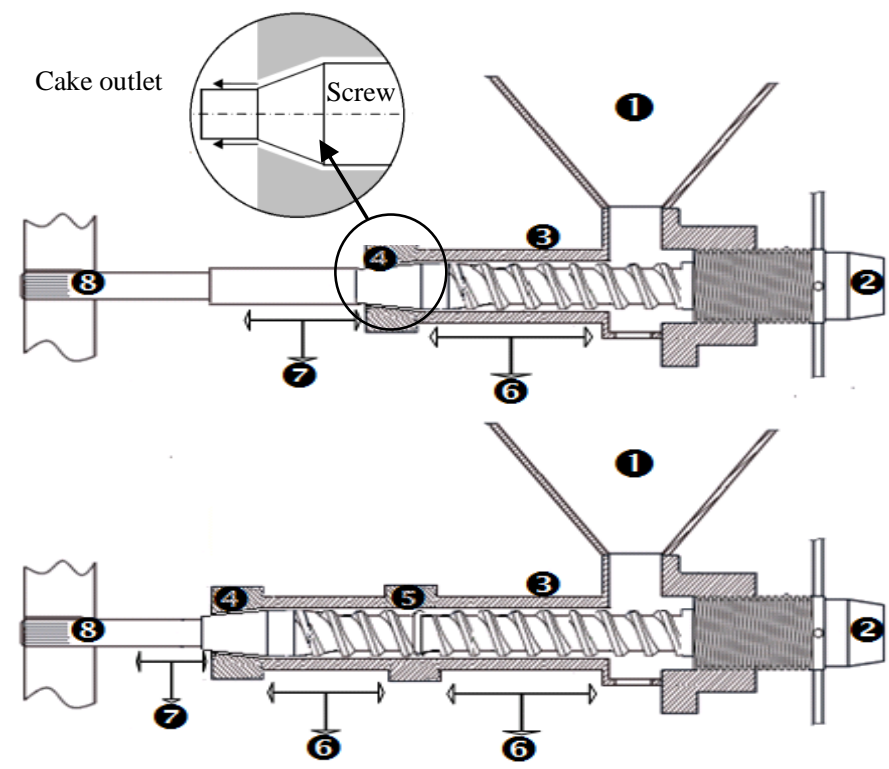

Figure (2): One and two stage oil expression unit.

1-Hopper 2-Choke adjustment 3-Cage 4-Choke 5-Intermediate choke 6-Oil outlet 7-Cake outlet 8-Screw shaft 9-Motor 10-Frame 11- Oil collector 12- Differential unit 


\section{Methods:}

Experiments were conducted to study performance and efficiency of oil expression unit. The tested parameters were:

(1) Seed moisture content: $6 \%, 8 \%$ and 10\% M.C.,

(2) Machine settings: one stage and two stage machine setting,

(3) Choke gap clearance: 0.5, 0.8, 1.1 and $1.4 \mathrm{~mm}$,

(4) Screw shaft speeds: 30, 50, 70 and $90 \mathrm{rpm}$, and

(5) For double stage machine, intermediate choke gap clearance: 0.6, $0.8,1.0$ and $1.2 \mathrm{~mm}$.

\section{Experimental procedure:}

The description of a typical experiment is used to explain the experimental procedure. First, the screw shaft rotational speed and choke gap were adjusted. Three LM35 temperature sensors located in the hopper; on the outer surface of a button expeller bar and on the choke outlet measured temperature changes. Before starting the measurement, the expression machine required preheating to $40^{\circ} \mathrm{C}$ by normal operation using pressed cake. After that seeds were used to measure the expression temperature. Expression temperature was measured until reaching to stable temperature for about three minutes. Whereupon the expression machine is empty. Sample of $5 \mathrm{~kg}$ seed was used to determine the productivity. It was difficult to determine the instant at which the pressing was finished. Therefore, the time measurement was started when the Ammeter showed a steep increase after seeds were fed, and stopped once Ammeter drastically declined while the press was almost empty (Beernes 2007). Crude oil was collected at the oil outlet and press cake was also collected from choke outlet.

Estimating the oil expression efficiency:

Oil expression efficiency is defined as the ratio of filtered oil expressed to the total oil content in the oilseeds. According to Sivakumoran (1983) oil content of each sample was expressed on a moisture free basis.

It was calculated as follows:

Expression efficiency $\%=\frac{W}{W o} * 100$ 
Where:

Wo $=$ Oil content in the oil seed, $\mathrm{kg}$ and $\mathrm{W}=$ Oil expressed $\mathrm{kg}$.

Oil expression cost:

Cost of operation was calculated according to the equation given by Awady (1978), in the following form:

$$
\mathrm{C}=\mathrm{p} / \mathrm{h}(1 / \mathrm{a}+\mathrm{i}+\mathrm{t} / 2+\mathrm{r})+(\mathrm{Ec} * \mathrm{Ep})+\mathrm{m} / 144,
$$

Where: $\mathrm{C}=$ hourly cost, $\mathrm{p}=$ price of machine, $\mathrm{h}=$ yearly working hours, $\mathrm{a}=$ life expectancy of the machine, $\mathrm{i}=$ interest rate/year, $\mathrm{t}=$ taxes, $\mathrm{r}$ $=$ overheads and indirect cost ratio, $\mathrm{Ec}=$ Electricity consumption $\mathrm{kW}$, $\mathrm{Ep}=$ Electricity price L.E/kW.h, "144" are estimated monthly working hours. Notice that all units have to be consistent to result in L.E/h.

Production cost, L.E./ton = Operation cost,( L.E./h) / Machine productivity, (ton/h)

\section{RESULTS AND DISCUSSION}

\section{1- Physical and mechanical properties of sunflower seeds:}

Properties of sunflower seeds were measured. Table (1) shows the properties of the sunflower seed processed by the machine

Table(1): Properties of sunflower seed used in the test.

\begin{tabular}{|c|c|c|c|c|c|c|c|c|}
\hline $\begin{array}{c}\text { M.C, } \\
\text { \% d.b. }\end{array}$ & $\begin{array}{c}\text { L, } \\
\mathbf{m m} .\end{array}$ & $\begin{array}{c}\text { W, } \\
\mathbf{m m} .\end{array}$ & $\begin{array}{c}\text { T, } \\
\mathbf{m m} .\end{array}$ & M, g. & $\begin{array}{c}\text { True } \\
\text { density, } \\
\mathbf{k g} / \mathbf{~ m}^{3}\end{array}$ & $\begin{array}{c}\text { Bulk } \\
\text { density, } \\
\mathbf{k g} / \mathbf{m}^{3}\end{array}$ & $\begin{array}{c}\text { Angle of } \\
\text { repose, } \\
\text { deg. }\end{array}$ & $\begin{array}{c}\text { Coefficient } \\
\text { of friction }\end{array}$ \\
\hline 6 & 11.74 & 5.83 & 3.42 & $\mathbf{0 . 0 7 2}$ & 650 & 392 & 30.7 & 0.47 \\
\hline 8 & 11.76 & 5.84 & 3.44 & $\mathbf{0 . 0 7 3}$ & 658 & 388 & 31.2 & 0.49 \\
\hline 10 & 11.8 & 5.84 & 3.45 & $\mathbf{0 . 0 7 4}$ & 669 & 385 & 31.5 & $\mathbf{0 . 5 2}$ \\
\hline
\end{tabular}

$\mathrm{L}=$ Length, $\mathrm{W}=$ Width, $\mathrm{T}=$ Thickness and $\mathrm{M}=$ Mass.

\section{2- Seed processing rate:}

Fig. 3 shows the effect of choke gaps, screw rotational speeds, seed moisture contents, and machine settings on the seed processing rate

\section{- Effect of choke gap on the seed feeding rate:}

Decreasing the choke opening decreases the seed processing rate. The narrow choke gap reduces the flow of the material inside the expression cage. High pressure is generated to overcome this resistance, which means increase in the expression duration. 


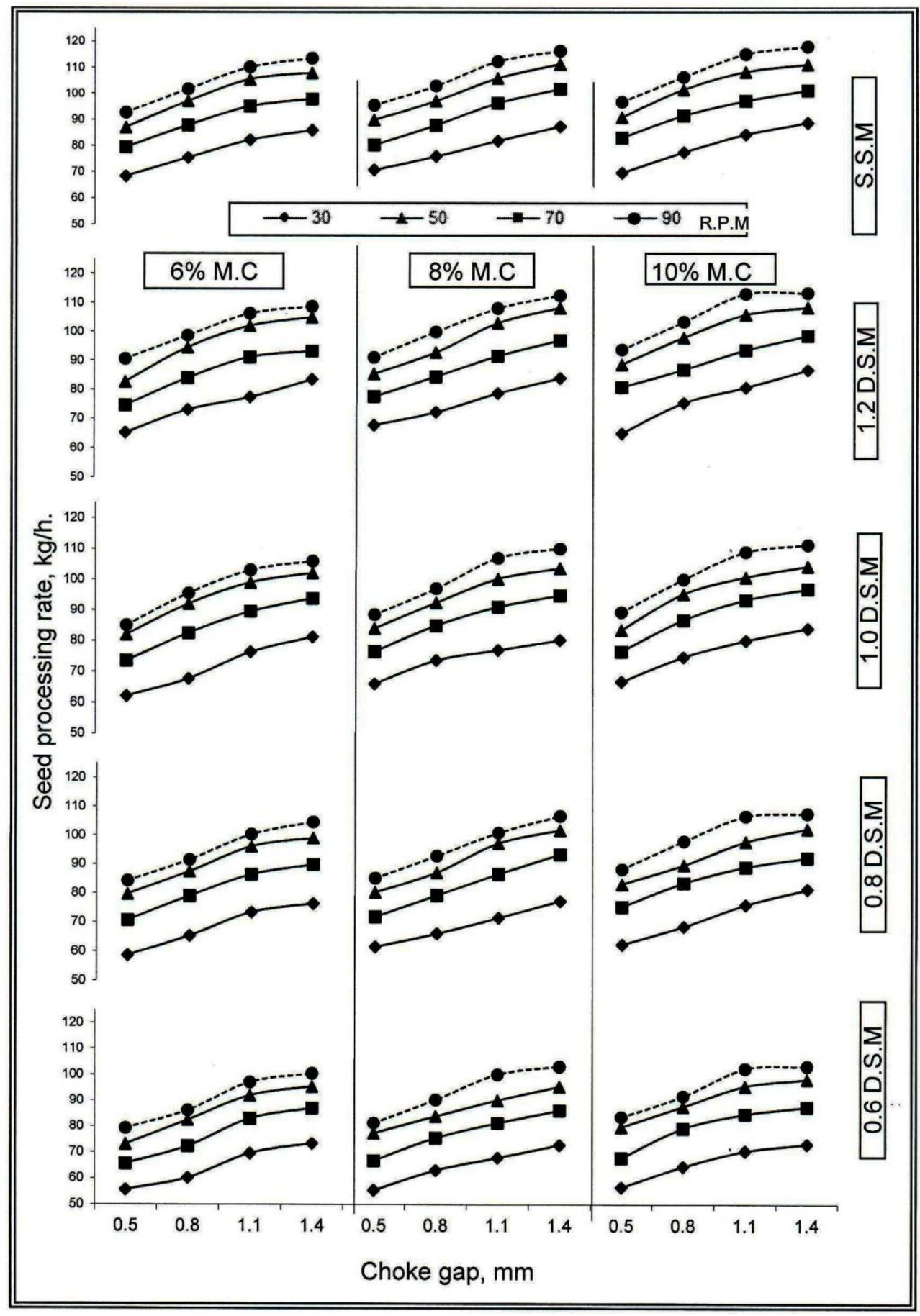

Fig.(3) Effect of choke gaps, screw speeds, moisture contents and machine settings on the seed processing rate, $\mathrm{kg} / \mathrm{h}$ 
When the choke discharge opening increased from 0.5 to $1.4 \mathrm{~mm}$ tended to increase seed processing rate from $75.35,72.89,67.58,65.23$ and 60.13 to $101.62,98.56,95.4,91.4,86.11 \mathrm{~kg} / \mathrm{h}$ for single stage machine, and double stage machine with $1.2,1.0,0.8$ and $0.6 \mathrm{~mm}$ intermediate choke gap at $50 \mathrm{rpm}$ screw rotational speed and $6 \%$ seed moisture content.

\section{- Effect of screw rotational speed on the seed feeding rate}

-Increasing the screw speed tends to increase the seed processing rate.

Increasing screw rotational speed from 30 to $90 \mathrm{rpm}$ tended to increase in seed processing rate from $83,80.56,76.24,75.1$ and 67.66 to $101,98.27$, $96.49,91.9$ and $87.4 \mathrm{~kg} / \mathrm{h}$ for single stage machine, and double stage machine with 1.2, 1.0, 0.8 and $0.6 \mathrm{~mm}$ intermediate choke gap respectively at $10 \%$ seed moisture content and $0.8 \mathrm{~mm}$ choke gap.

\section{-Effect of moisture content on the seed processing rate}

The results show that with increasing moisture content, the seed processing rate increases.

It was noticed that when the seed moisture content increased from 6 to 10 $\%$ tended to increase in seed processing rate from 85.85 to $88.6 \mathrm{~kg} / \mathrm{h}$ for single stage machine, and from 83.32 to $86.39 \mathrm{~kg} / \mathrm{h}$ for double stage machine with $1.2 \mathrm{~mm}$ intermediate choke gap and; from 81.02 to 83.56 for double stage machine with $1.0 \mathrm{~mm}$ intermediate choke gap; and from 76.2 to $81 \mathrm{~kg} / \mathrm{h}$ for double stage machine with $0.8 \mathrm{~mm}$ intermediate choke gap at $90 \mathrm{rpm}$ screw rotational speed and $0.5 \mathrm{~mm}$ choke gap.

\section{-Effect of the machine settings on the seed processing rate}

The seed processing rate in general decreases in double stage machine settings. This may be due to an increase in the length of the screw and also due to pressing of the fed oilseed twice rather than once prior to its exit from the barrel.

\section{3- Expressed oil productivity:}

Fig. 4 shows the effect of choke gaps, screw rotational speeds, seed moisture contents, and machine settings on the expressed oil productivity. 


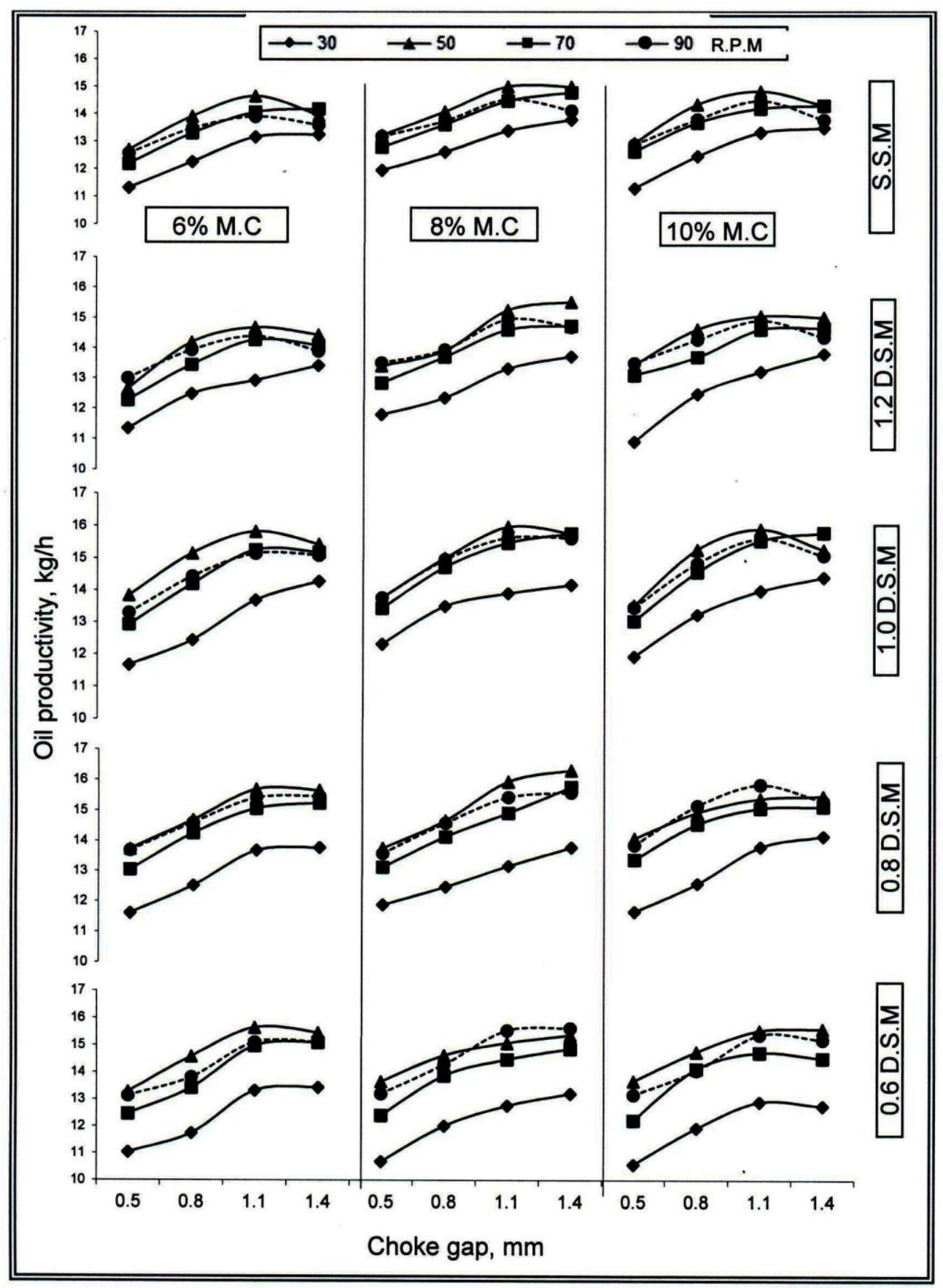

Fig.(4): Effect of choke gaps, screw speeds, moisture contents and machine settings on the oil productivity, $\mathrm{kg} / \mathrm{h}$ 


\section{-Effect of choke gap on the expressed oil productivity}

Reducing the opening discharge area decreases the expressed oil productivity. This may be explained by decreased seed material flow.

When the choke discharge opening increased from 0.5 to $1.4 \mathrm{~mm}$, oil productivity increased from $11.94,11.78,12.29,11.86$ and 10.68 to $13.17,13.49,13.75,13.57$ and $13.2 \mathrm{~kg} / \mathrm{h}$ for single stage machine, and double stage machine with 1.2, 1.0, 0.8 and $0.6 \mathrm{~mm}$ intermediate choke gap at $30 \mathrm{rpm}$ screw rotational speed and $8 \%$ seed moisture content.

\section{-Effect of screw rotational speed on the oil productivity}

Increasing screw rotational speed tends to increase the oil productivity.

Increasing screw rotational speed from 30 to $90 \mathrm{rpm}$, oil productivity increased from 12.56, 12.99, 13.29, 13.68 and 13.13 to 13.58, 13.88, $15.07,15.45$ and $15.1 \mathrm{~kg} / \mathrm{h}$ for single stage machine, and double stage machine with $1.2,1.0,0.8$ and $0.6 \mathrm{~mm}$ intermediate choke gap respectively at $6 \%$ moisture content and $0.5 \mathrm{~mm}$ choke gap.

\section{-Effect of moisture content on the expressed oil productivity}

As explained before, increasing in seed moisture content tends to increases in the seed processing rate, but on the other hand, it also tends to decrease the seed oil content. So the seed moisture content has a little effect on the expressed oil productivity.

Maximum expressed oil productivity was obtained at $8 \%$ moisture content at most different rotational screw speeds; choke gaps, and machine settings.

It was noticed that the seed moisture content increase from 6 to $8 \%$ tended to change the expressed oil from 11.31, 11.34, 11.66, 11.6 and 11.03 to $11.94,11.78,12.29,11.86$ and $10.68 \mathrm{~kg} / \mathrm{h}$ for single stage machine, and double stage machine with $1.2,1.0,0.8$ and $0.6 \mathrm{~mm}$ intermediate choke gap respectively at $30 \mathrm{rpm}$ screw rotational speed and $0.5 \mathrm{~mm}$ choke gap. On the other hand, increasing seed moisture content from 8 to $10 \%$ tends to change the expressed oil from 11.94, 11.78, $12.29,11.86$ and 10.68 to $11.28,10.88,11.9,11.63$ and $10.57 \mathrm{~kg} / \mathrm{h}$ for single stage machine, and double stage machine with 1.2, 1.0, 0.8 and 0.6 $\mathrm{mm}$ intermediate choke gap respectively at the same conditions.

\section{Effect of machine settings on the expressed oil productivity}

The expressed oil productivity increases in double stage machine settings. This may be due to an increase in the length of the screw which 
means more expression duration and also due to pressing of the fed oilseed twice rather than once prior to its exit from the barrel.

When the single stage screw setting machine is used, the expressed oil productivity was $14.99 \mathrm{~kg} / \mathrm{h}$. using a double stage machine arrangement with $1.2 \mathrm{~mm}$ intermediate choke tends to increase in expressed oil productivity to $15.23 \mathrm{~kg} / \mathrm{h}$. Changing intermediate choke to $1.0 \mathrm{~mm}$ tends to increase the expressed oil productivity to $15.94 \mathrm{~kg} / \mathrm{h}$ at $8 \%$ moisture content and $1.1 \mathrm{~mm}$ choke gap.

\section{4- Oil expression efficiency:}

Fig. 5 shows the effect of choke gaps, screw rotational speeds, seed moisture contents, and machine settings on the oil expression efficiency

\section{-Effect of choke gap on the expression efficiency}

The outlet clearance was the most important designation parameter that controls the other variables of oil expression process as well as the output material characteristics. Decreasing the choke opening, decreases cake oil content and increasing oil recovery. The narrow choke gap may reduce the flow of the material inside the expression cage that may increase the duration of extraction also include more seed breakage and fine size of the seed material that may contribute higher expression efficiency.

When the choke discharge opening increased from 0.5 to $1.4 \mathrm{~mm}$ it tended to decrease oil expression efficiency from 75.1, 77.5, 82.9, 85.7 and 85.7 to $61.3,65.9,69.2,71.0$ and $72.3 \%$ for single stage machine, and double stage machine with 1.2, 1.0, 0.8 and $0.6 \mathrm{~mm}$ intermediate choke gap at $30 \mathrm{rpm}$ screw rotational speed and $8 \%$ seed moisture content.

\section{Effect of screw rotational speed on the expression efficiency}

Results show a reduction in oil expression efficiency by increasing rotational speed. This behavior may be explained increasing the throughput. Increased throughput means reduced expression duration and thus less chance for the oil to flow from between the solid material. 


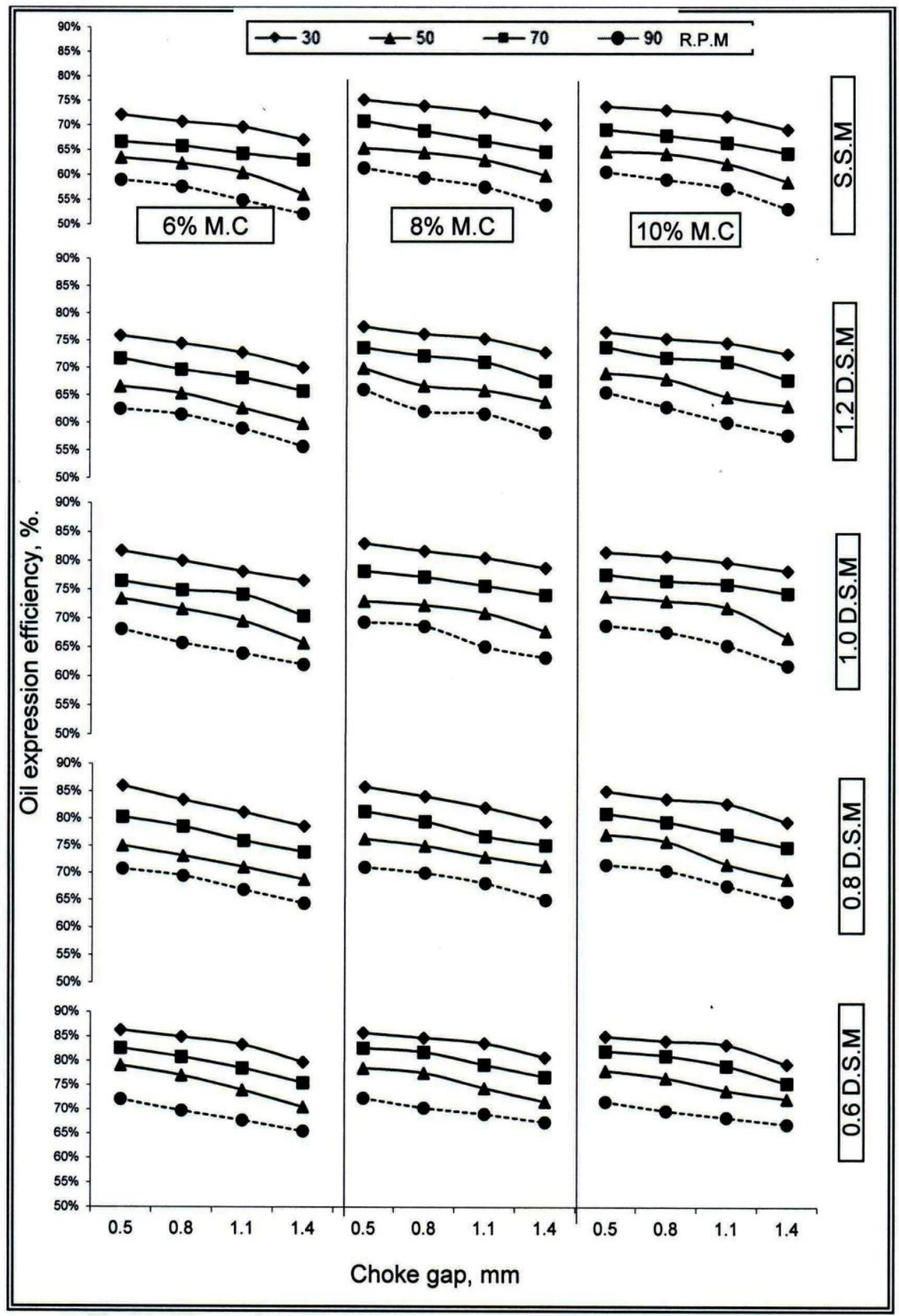

Fig.(5): Effect of choke gaps, screw speeds, moisture contents and machine settings on the oil expression efficiency.\% 。 
Increasing screw rotational speed from 30 to $90 \mathrm{rpm}$ tended to decrease in oil expression efficiency from 72.1, 75.9, 81.7, 86.0 and 86.3 to 67.0, $69.9,76.5,78.5$ and $79.7 \%$ for single stage machine, and double stage machine with $1.2,1.0,0.8$ and $0.6 \mathrm{~mm}$ intermediate choke gap respectively at $6 \%$ moisture content and $0.5 \mathrm{~mm}$ choke gap.

\section{Effect of moisture content on the expression efficiency}

The effect of moisture content on oil expression efficiency is considerable. Higher seed moisture content reduces the temperature of the expression and increases the flow rate inside the expression cage.

Maximum oil recovery was obtained at seeds moisture content $8 \%$ (d.b). The oil expression efficiency increased by increasing seeds moisturecontent from 6 to $8 \%$ and decreased by increasing seeds moisture-content from 8 to $10 \%$ for all tested screw speeds, choke gaps and machine settings.

\section{Effect of machine settings on the expression efficiency}

The expression efficiency was increased by using double stage machine. This may be due to the increase in screw length which means exposing the fed oilseed to longer time pressure and also due to an additional intermediate choke which tends to press the fed oilseed twice rather than once prior to its exit from the barrel cage.

When the single stage screw setting machine was used the oil expression efficiency was 65.4. \%. Using a double stage machine arrangement with $1.2 \mathrm{~mm}$ intermediate choke tends to increase oil expression efficiency to $69.8 \%$. Changing intermediate choke to $1.0 \mathrm{~mm}$ tends to increase the oil expression efficiency to 72.9 at $8 \%$ moisture content, $30 \mathrm{rpm}$ screw rotational speed and $1.1 \mathrm{~mm}$ choke gap.

\section{5-The expressed oil temperature:}

Fig. 6 shows the effect of choke gaps, screw rotational speeds, seed moisture contents, and machine settings on the expressed oil temperature. Oil temperature less than $70 \mathrm{C}^{\circ}$, during the pressing operation, may help processors satisfy the cold pressing requirement of organic oil.

\section{Effect of choke gap on the oil temperature}

Decreasing the choke opening increases oil temperature. This may be due to the friction forces between material, screw and barrel cage. 


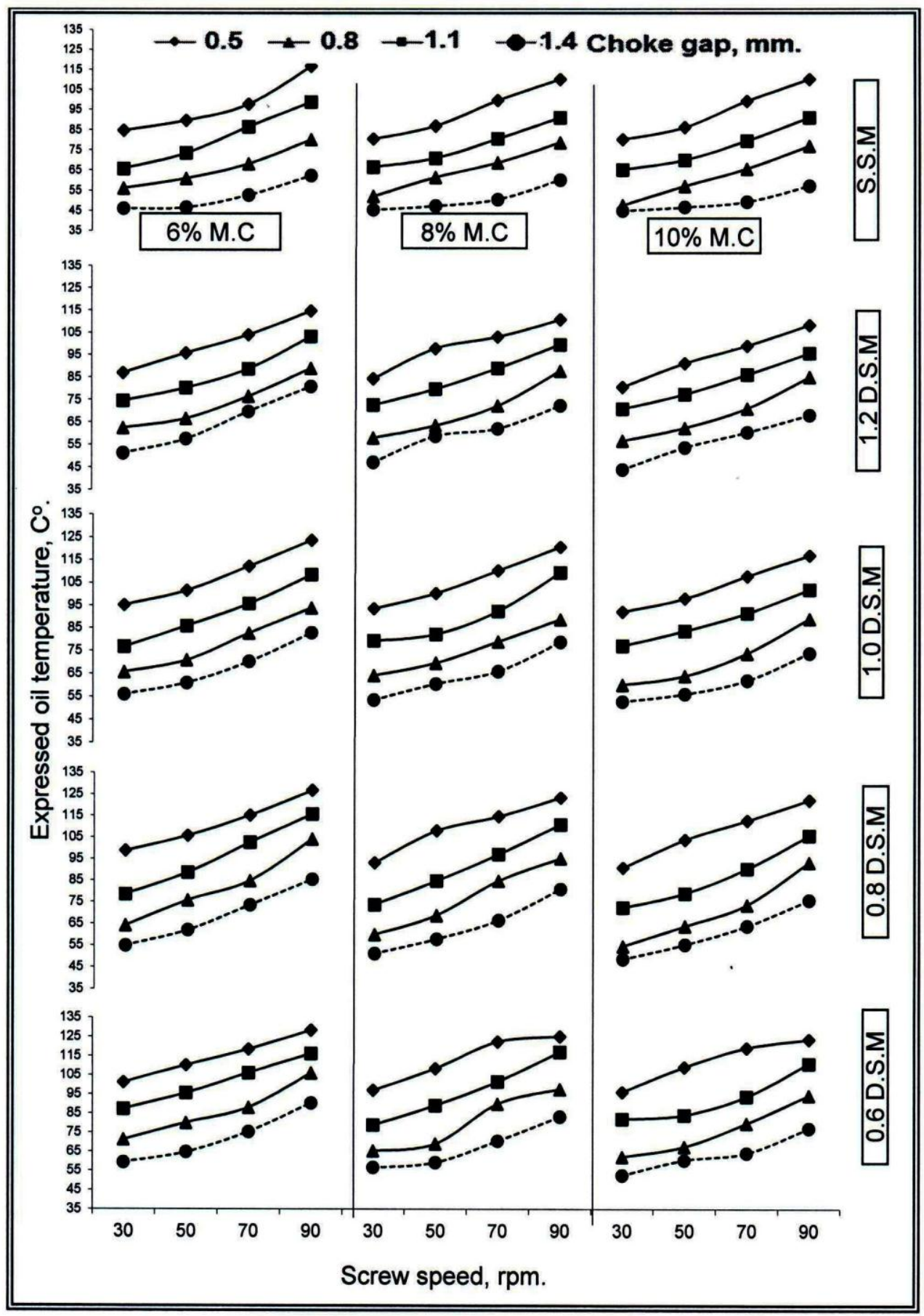

Fig.(6): Effect of choke gaps, screw speeds, moisture contents and machine settings on the expressed oil temperature, $\mathrm{C}^{\mathrm{o}}$. 
This friction forces were increased by the increasing the resistance to flow at the end of the screw press. decreasing choke discharge opening from 1.4 to $0.5 \mathrm{~mm}$ tended to increase in oil temperature from $80.3,84$, 93.2, 92.9 and 96.9 to $110,110.5,120.3,123$ and 125 Co for single stage machine, and double stage machine with $1.2,1.0,0.8$ and $0.6 \mathrm{~mm}$ intermediate choke gap at $30 \mathrm{rpm}$ screw rotational speed and $8 \%$ seed moisture content.

\section{Effect of screw rotational speed on the oil temperature}

Increasing the screw rotational speed increases oil temperature.

Increasing screw rotational speed from 30 to $90 \mathrm{rpm}$ tended to increase in oil temperature from $65.0,70.6,76.6,72$ and 82 to 90.8, 95.3, 101.4, 105.3 and $110.8 \mathrm{C}^{\circ}$ for single stage machine, and double stage machine with $1.2,1.0,0.8$ and $0.6 \mathrm{~mm}$ intermediate choke gap respectively at $10 \%$ moisture content and $0.8 \mathrm{~mm}$ choke gap.

\section{Effect of moisture content on the oil and cake temperature}

Increasing moisture content tends to decrease oil temperature. This was explained by Willems (2007) who suggested that during expression, water can only be removed by evaporation bringing up another contribution to the cooling effect. Also Singh et al. (2002) suggested that moisture acts as a lubricant during pressing.

Increasing moisture content from 6 to $10 \%$ tended to decrease in oil temperature from $116.5,114.4,123.4,126.5$ and 128.2 to 101,108 , 116.4, 121.7 and $123.4 \mathrm{C}^{0}$ for single stage machine, and double stage machine with $1.2,1.0,0.8$ and $0.6 \mathrm{~mm}$ intermediate choke gap respectively at $90 \mathrm{rpm}$ screw rotational speed and $0.5 \mathrm{~mm}$ choke gap.

The oil temperature in general increases in double stage machine settings. This may be due to an increase in the length of the screw which means more friction upon the seeds between the screw and parallel cage.

\section{6-Oil expression cost:}

Fig. 7 shows the effect of choke gaps, screw rotational speeds, seed moisture contents, and machine settings on the oil expression cost. 


\section{Effect of choke gaps on the oil expression cost per L.E/ton}

Decreasing the choke opening increases the expression oil cost. Decreasing choke gap outlet from 1.4 to 0.5 tends to increase oil expression cost from 660.46 to $581.99,667.53$ to $571.95,661.21$ to $559.8,669.83$ to 544.56 and finally from 706.24 to 571.95 L.E./ton for single stage machine and double stage machine arrangement with 1.2 , $1.0,0.8$ and $0.6 \mathrm{~mm}$ intermediate choke respectively at $6 \%$ moisture content and $30 \mathrm{rpm}$ screw rotational speed.

\section{Effect of screw rotational speed on the oil expression cost}

Increasing the screw rotational speed decreases oil expression cost, this effect may be due to increase in throughputs rate.

Increasing screw rotational speed from 30 to 90 oil expression cost decreased from 656.06 to $583.21,693.95$ to $575.87,643.69$ to 561.3 , 664.68 to 572.56 and finally from 733.2 to $639.22 \mathrm{~L}$.E/ton for single stage machine and double stage machine arrangement with 1.2, 1.0, 0.8 and $0.6 \mathrm{~mm}$ intermediate choke respectively at $10 \%$ moisture content and $0.5 \mathrm{~mm}$ choke gap.

\section{Effect of moisture content on the oil expression cost}

Seed moisture content has a little effect on the oil expression cost. Increasing the seeds moisture content tended to slight decrease in the expression cost.

Increasing seed moisture content from 6 to $10 \%$ oil expression cost increased from 623.65 to $608.50,619.89$ to $619.76,630.73$ to 593.19 , 634.68 to 625.81 , and finally from 679.71 to 665.54 L.E./ton for single stage machine and double stage machine arrangement with 1.2, 1.0, 0.8 and $0.6 \mathrm{~mm}$ intermediate choke respectively at 50 rotational speed and $0.5 \mathrm{~mm}$ choke gap

\section{Effect of machine settings on the oil expression cost}

Oil expression cost increased in double stage machine settings this may be due to an increase in the length of the screw, which means more power consumption and more expression residual time.

When the single stage screw machine setting is used, the oil expression cost was 560.99 L.E./ton. Using a double stages machine arrangement with $1.2 \mathrm{~mm}$ intermediate choke tends to increase in oil expression cost to 549.39. L.E./ton. Changing intermediate choke to be $1.0 \mathrm{~mm}$ tends to increase oil expression cost to be 549.1 L.E./ton. 


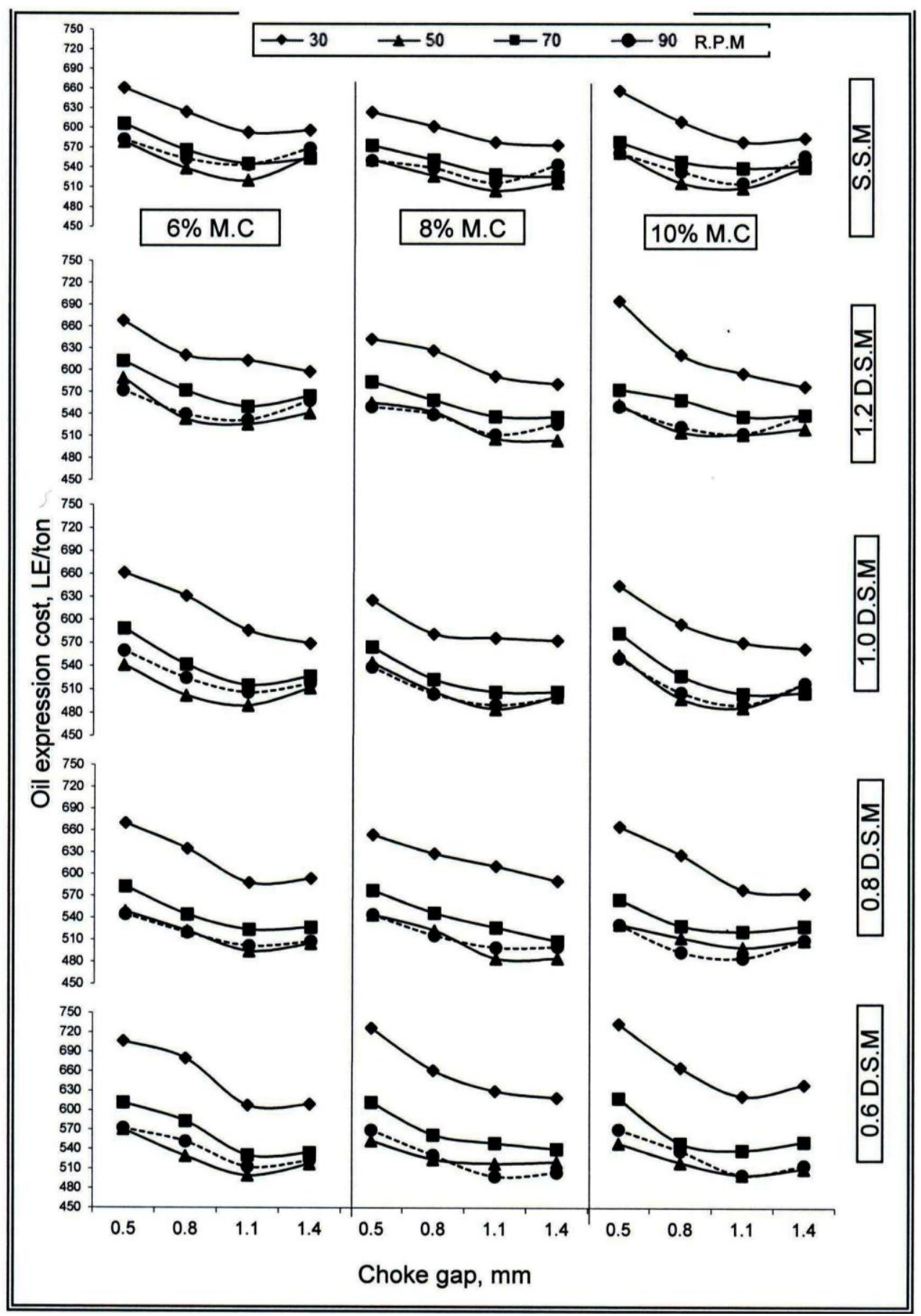

Fig.(7): Effect of choke gaps, screw speeds, moisture contents and machine settings on the oil expression cost, LE/ton. 
Changing intermediate choke to be $0.8 \mathrm{~mm}$ tends to increase oil expression cost to be 530.34 L.E./ton. Finally changing intermediate choke to be $0.6 \mathrm{~mm}$ tends to increase oil expression cost to be 569.91 L.E./ton at $10 \%$ moisture content and $1.4 \mathrm{~mm}$ choke gap.

\section{SUMMARY AND CONCLUSION}

The optimum conditions of oil production by the developed machine are different according to many parameters. From the oil expression efficiency view, the maximum oil expression efficiency of $86 \%$ was obtained with $0.5 \mathrm{~mm}$ choke gap clearance, $30 \mathrm{rpm}$ screw rotational speed, $6 \%$ seed moisture content and double stage machine with $0.6 \mathrm{~mm}$ intermediate choke. From the oil productivity side of view, the maximum oil productivity of $16.28 \mathrm{~kg} / \mathrm{h}$ was obtained with $1.1 \mathrm{~mm}$ choke gap clearance, $90 \mathrm{rpm}$ screw rotational speed, $8 \%$ seed moisture content and double stage machine with $0.8 \mathrm{~mm}$ intermediate choke. For the processed oil temperature, the minimum expressed oil temperature of $43.66 \mathrm{C}^{\mathrm{o}}$ was obtained with $1.4 \mathrm{~mm}$ choke gap, $10 \%$ seed moisture content, $30 \mathrm{rpm}$ screw rotational speed and double stage machine with $1 . r \mathrm{~mm}$ intermediate choke machine setting. Finally from the produced oil cost view the minimum expressed oil cost of 484.29 LE/ton was obtained with $1.1 \mathrm{~mm}$ choke gap, $8 \%$ seed moisture content, $70 \mathrm{rpm}$ screw rotational speed and double stage machine with $0.8 \mathrm{~mm}$ intermediate choke machine setting

\section{REFERENCES}

Al-Ashry, A. (1999) Development of a sample machine for expression of some oilseeds. Ph.D. Th., Uni. of Monofia.

Amin I. A., F. A. Shafik, And N. Y. Soliman. (2007). Production expansion potentials for edible corn oil in Egypt. National Research Centre, Egypt. J. of App. Sci. Res., 3(1): 50-55.

Awady, M. N., (1978), Engineering of tractors and agricultural machinery, Text Bk.,Col. Ag., Ain-Shams U., $5^{\text {Th }}$ Ed.:164-167. ( In Arabic updating 1998 ).

Beerens, P. (2007) Screw-pressing of jatropha seeds for fuelling purposes in less developed countries. M.Sc. Th. Eindhoven. Uni. of Tech. Netherlands: 1-2 
Singh Kk, D. P. Wiesenborn , K. Tostenson And N. Kangas (2002) Influence of moisture content and cooking on screw pressing of crambe seed. J. Am. Oil Chem. Soc. USA (79):165-170.

Sivakumaran, K., And J. W. Goodrum (1987). Influence of internal pressure on performance of a screw expeller. ASAE (30): 11671171.

Willems, P. (2007) Gas assisted mechanical expression of oilseeds: Ph.D. Th., Uni. of Twente, Netherlands: 32.

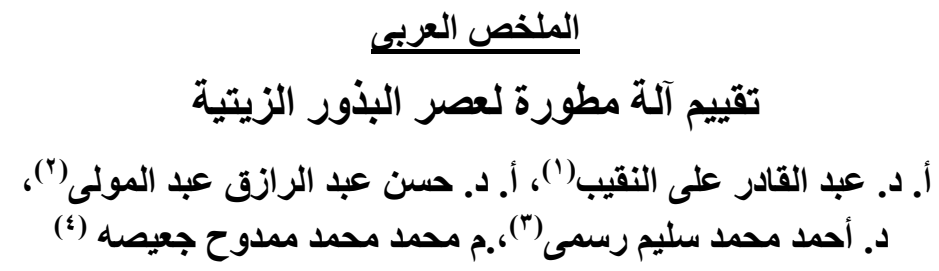

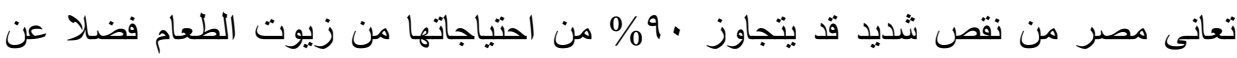

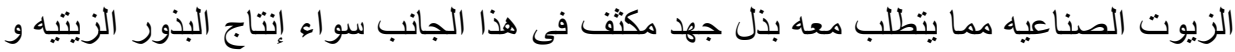

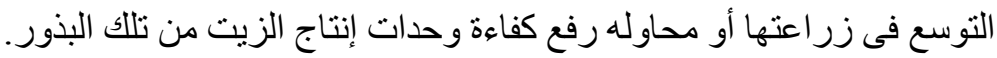

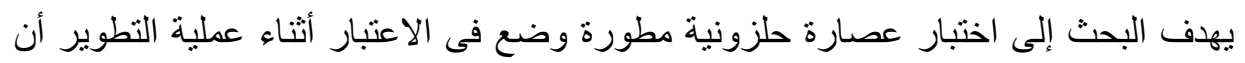

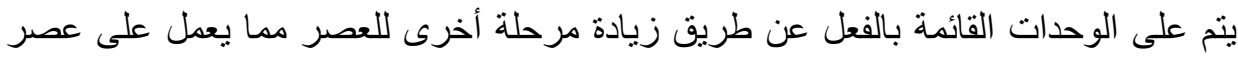

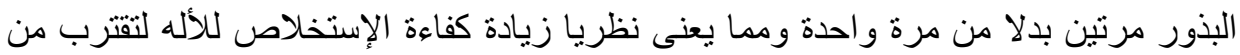

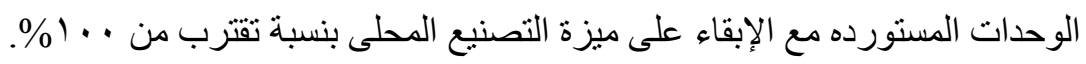

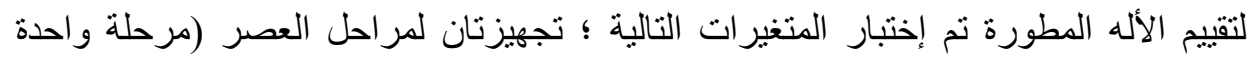

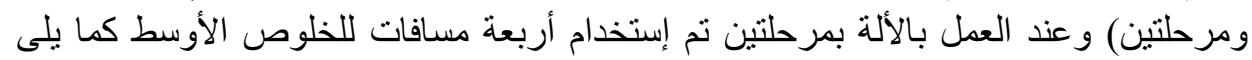

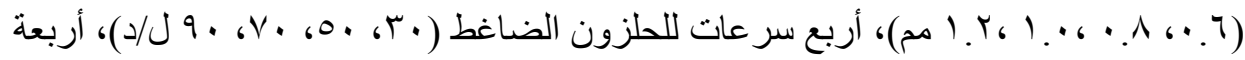

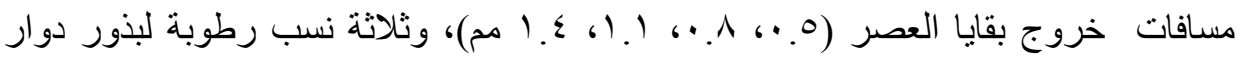

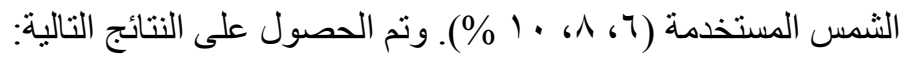

(1) الخصائص الطبيعية و الميكانيكية لبذور دوار الثمس: وجد أن أن هنالك علاقة طرديه بين الطين

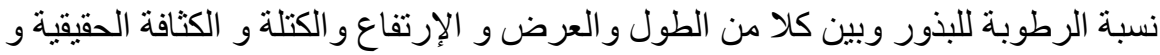

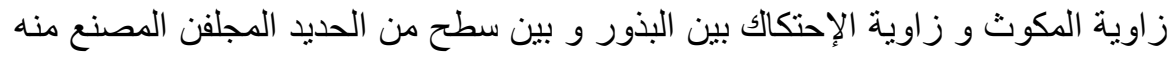

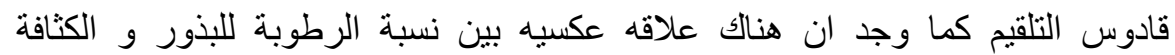

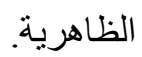

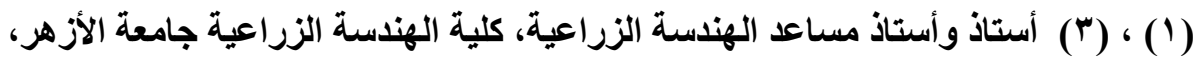

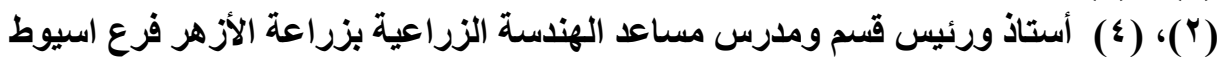




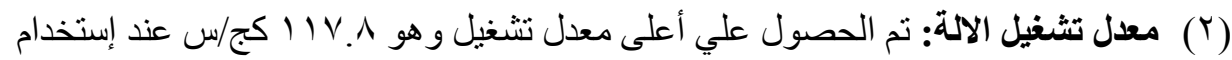

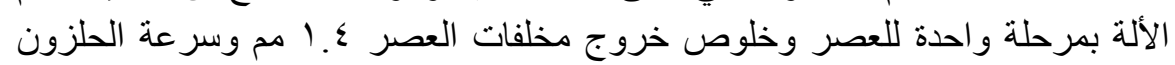

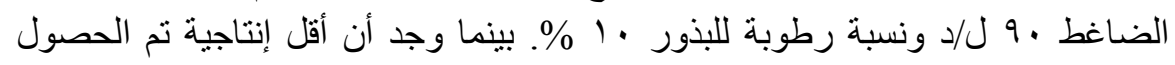

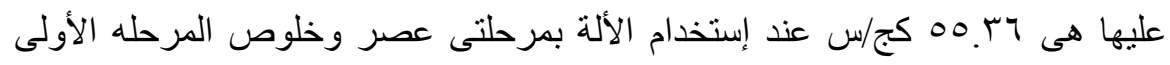
7.

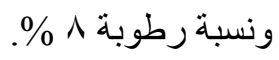

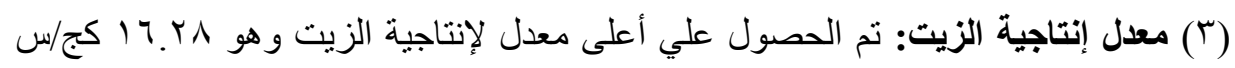

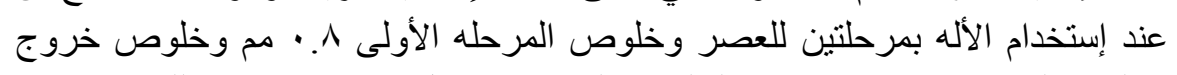

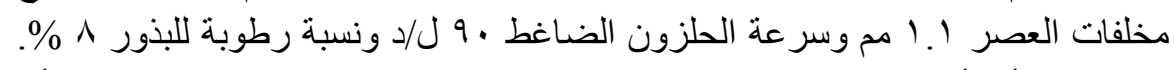

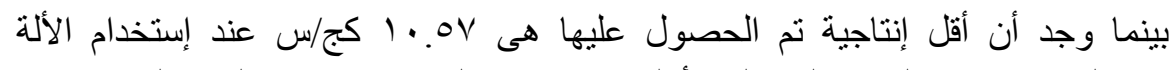

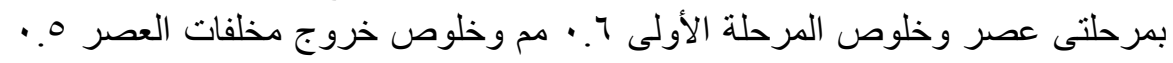

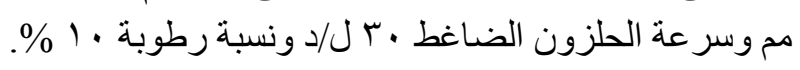

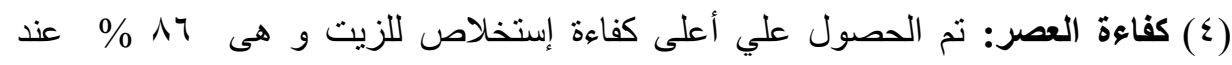

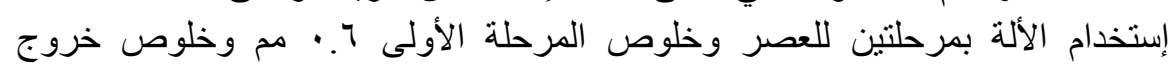

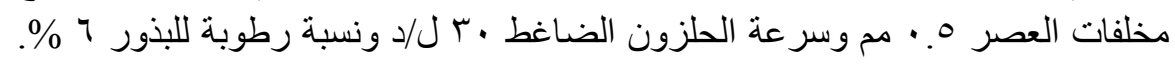

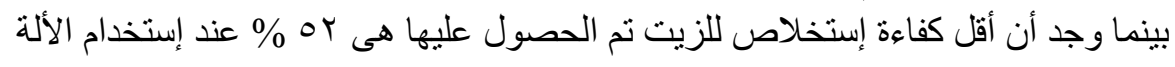

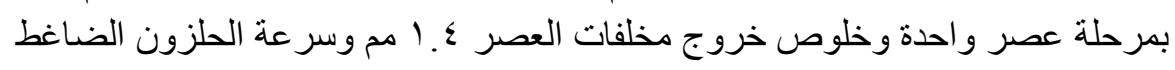

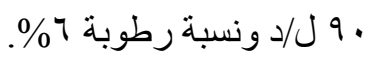
(0) درجة حرارة الزيت: كلما انخفضت درجة حرة ارة ارة الزيت المعصور كلما زادت قيمتة

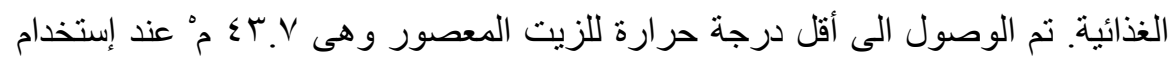

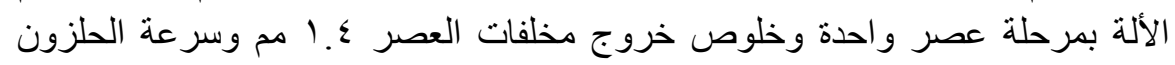

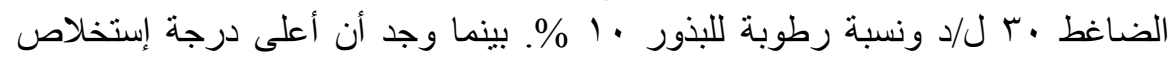

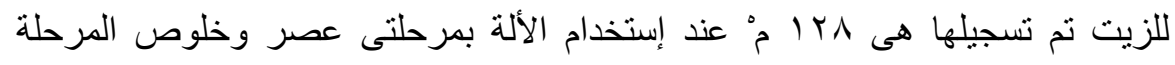
الأولى 7.

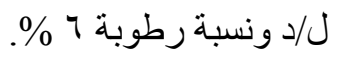

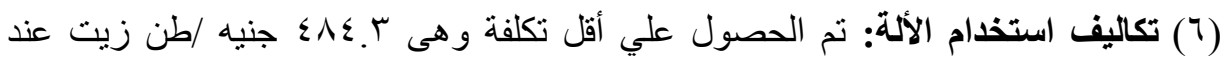

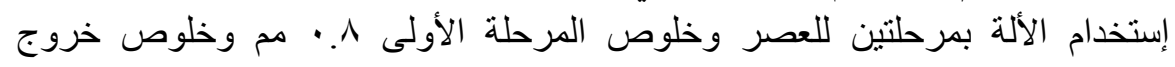

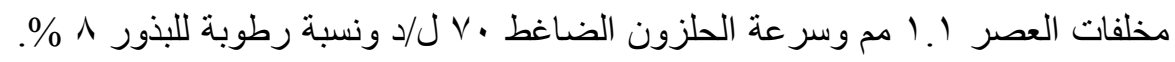

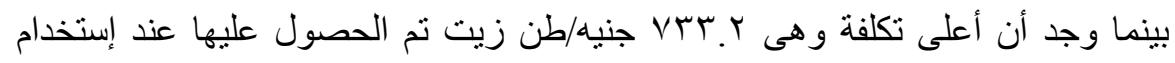

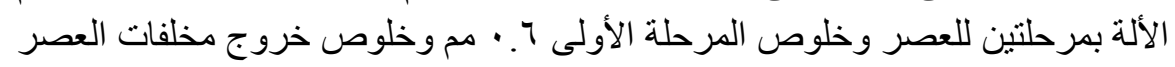

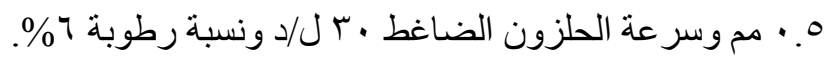

